\title{
Assessment of Factors That Affect the Performance of Agricultural Production, in the Case of Amhara Region, Ethiopia
}

\author{
Melkamu Ayana Zeru \\ Department of Statistics, Haramaya University, Harar, Ethiopia \\ Email:melkamu.ayana@gmail.com
}

How to cite this paper: Zeru, M.A. (2018) Assessment of Factors That Affect the Performance of Agricultural Production, in the Case of Amhara Region, Ethiopia. Agricultural Sciences, 9, 1058-1069. https://doi.org/10.4236/as.2018.98073

Received: June 12, 2018

Accepted: August 27, 2018

Published: August 30, 2018

Copyright $\odot 2018$ by author and Scientific Research Publishing Inc. This work is licensed under the Creative Commons Attribution International License (CC BY 4.0).

http://creativecommons.org/licenses/by/4.0/

Open Access

\begin{abstract}
The agricultural sector is the basis of livelihood for a large proportion of society in Ethiopia. In the three political regimes in modern Ethiopia, the Imperial, the military and the Ethiopian people revolutionary democratic front (EPRDF), agriculture has been regarded as a critical sector. The Agricultural Development Led Industrialization (ADLI) is the national policy of the country. Regardless of the government policy attention and investment, there is a long way to go for smallholders to ensure food self-sufficiency. Agriculture is the base of our food, transformation to industrialization, climatic change control system. Agriculture is the soul of our sovereignty for development as well as poverty reduction for individuals and country level. In Ethiopia, population density is high and has been increasing and agricultural land has been decreasing because of fragmenting or converting it into residential plots. To meet the domestic food requirements, use of improved production technologies developed by research is come out to be important. Therefore, the goal of this study was to analyze factors that affect the performance of agricultural products in Amahara region national state and to determine the highly significant input factors for producing high and qualified agricultural outputs. Data regarding total agricultural outputs and its input factors in study area of Amahara region from 2010 to 2018 was obtained from Amhara national state branch of the Ethiopian institute of agricultural sector. Correlation analyses were used to examine the strength of the relationship between each of the determinant factors with total agricultural output, while multiple regression analysis was employed to examine the simultaneous effects of several independent variables on the dependent variable, total agricultural outputs. These analyses were employed through the packages $\mathrm{R}$ and Stata to achieve the main objectives of the study. All of the independent variables were highly correlated with the total agricultural output. The overall regression model was
\end{abstract}


highly significant ( $\mathrm{p}$-value $<0.01$ ) with $\mathrm{F}=45.532$. The $\mathrm{R}$-squared value implies that $93.8 \%$ percent of the changes in average total agricultural outputs are successfully explained by the variables used in the model of this study. If we take model size into account, $91.8 \%$ percent of the variation in average total agricultural output was explained by the values of the independent variables. Specifically, among the independent variables irrigated land, fertilizer, improved seed and pesticides are the most significant factors for total products (p-value $<0.05$ ).

\section{Keywords}

Agriculture, Assessment, Total Output, Determinant Factors

\section{Introduction}

Nodaway, Agriculture is the base of our food, transformation to industrialization, climatic change control system. Agriculture is also the base the society for development as well as poverty reduction for individuals and in country level. The current government of Ethiopia is highly involved in the agricultural sector and, through its developmental state theory, has put the highest level of investment into the sector [1]. The agricultural production in our country come from both in private peasant holdings in large as well as in medium commercial farms, where the commercial farms consist of the state and private investment commercial frames [2]. Ethiopia is one of the largest African countries with a population of 73.9 million people. The country shares bound-arise with Eritrea to the north, Kenya to the south, Somalia to the east and Sudan to the west. According to the Central Statistical Agency [3] of Ethiopia, the majority (83.8\%) of Ethiopians reside in the rural areas. Hence, subsistence and rain-fed agriculture is the economic base and means of livelihood of the majority of these people. The contribution of agriculture to growth domestic product in Ethiopia is above the average contribution of Sub-Saharan Africa. The share of the agricultural sector in Sub-Saharan Africa is around 40 percent [4]. On the other hand, the contribution of the agricultural sector to GDP in Ethiopia is 41 percent [5]. In Ethiopia, population density is high and has been increasing and agricultural land has been decreasing because of fragmenting or converting it into residential plots. To meet the domestic food requirements, use of improved production technologies developed by research is come out to be important. Agriculture in our country is the foundation of the economy. The structure of this economy is characterized by an overall whelming depends up on agriculture. The contribution of agriculture to gross domestic product (GDP) is quite high about $40 \%$ of GDP in our country and the primary role of agriculture was to provide sufficient and low priced food as well as man power for the expanding of industrial economy which was through out to be the dynamic leading sector in any overall strategy of economy development [6]. 
Investment is one of the means of achieving agricultural development for the given appropriate strategy and favorable policy environment and the most volatile micro economic variable in which trying to achieve economic growth and development. We do not have strong observed growing faster than economic with strong state intervention [7]. In the last decade per capital agriculture production in Amahara is 5.6\% while population growing at 3\% per annual and hence food production has been below demand and it result in chronic food deficit and this poor performance of agricultural sector has an impact on the other sector of the economy [8].

Rapid population growth aggravates the problem of agricultural performance in the society where agricultural inputs like labor force, fertilizer, improved seed and pesticides are limited. Here is a considerable body of literature that favors the idea that agricultural growth serves as an engine of growth and that irrigation-led technological changes are the eye drivers behind the growth of productivity in the agriculture sector in Asia [9].

But, in Ethiopia, the ultimate goal of Agricultural Development Led Industrialization (ADLI) strategy is for the industry to take the lead.

Due to these limitation land productivity is stagnating, technological development is at rudimentary stage, and resource distributions are quite uneven.

Economists traditionally have analyzed the agricultural development in terms of its relationship to the growth of overall economy. While the physiatrists, Viewed agriculture as the engine of growth angling surpluses large enough to stimulate growth order sector of economy. On the other hand the classical economists believed that the diminishing of marginal returns to agricultural land would eventually lead to overall economic stag-nation or the stable condition [10]. As the majority of the population is engaged in the agricultural sector, it is the critical sector for the future. To show the importance of agriculture [11] stated that it is in the agricultural sector that the battle for long-term economic development will be won or lost. In the act of output in agricultural production uses a Variety of goods and services called factors (determinants) out puts. Past studies have already demonstrated that there are a number of factors that might simultaneously have contributed to agriculture growth in the world, the same as in Ethiopia. This factor includes labor force, irrigated land, improved seeds, fertilizer, pesticides and other related factors. Workers react on incentives, created by the institutional and economic environment, by changing their labor effort and thus the intensity of production factors to count for the different factors that affect production out-put, different production function shifters are include in the model [12] and [13]. Finally, Macours analyzed that the output is highly depends on labor force, temperature, irrigated land and improved seed but fertilizer is the insignificant variable. Among these variables the labor force and temperature has negative relationship with the output production while improved seed and irrigated land has positive or direct relationship with that of the output production. In some countries the evidence of an inverse relationship between 
farm irrigated land and its productivity is more mixed than elsewhere in our country. This is partly a result of imperfect policy distortions and also that the discrimination against smallholder farmers. Large farms have often been more pro table due to frequently occupy land of high quality, have better access to credit an extension services and use more non labor inputs, such as fertilizers, pesticides, high-yield seed varieties, and irrigation land.

The goal of this study was to analyze factors that affect the performance of agricultural products in Ethiopia particularly in Amhara regional state. The state of Amhara is located in the north western and north central part of Ethiopia. The State shares common borders with the state of Tigray in the north, Afar in the east, Oromiya in the south, Benishangul/Gumuz in the south west, and the Republic of Sudan in the west. Amhara is topographically divided into two main parts, namely the highlands and lowlands. The highlands are above 1500 meters above sea level and comprise the largest part of the northern and eastern parts of the region while the lowland part covers mainly the western and eastern parts with an altitude between 500 - 1500 meters above sea level. The annual mean temperature for most parts of the region lies between $15^{\circ} \mathrm{C}-21^{\circ} \mathrm{C}$. The State receives the highest percentage $(80 \%)$ of the total rainfall in the country. The highest rainfall occurs during the summer season, which starts in mid-June and ends in early September.

This study was basically conducted in order to determine the highly significant input factors for producing agricultural outputs and also to determine the type of relationship exist between the dependent and the predictor variables in the case of Amahara National state. In the process data regarding total agricultural outputs and its input factors with study, from 2010 to 2018 was obtained from Amahara state of the Ethiopian Institute of Agricultural Sector. Correlation analyses were used to examine the strength of the relationship between each of the determinant factors with total agricultural output, while multiple regression analysis was employed to examine the simultaneous effects of several independent variables on the dependent variable total agricultural outputs. These analyses were employed through the packages $\mathrm{R}$ and Stata to achieve the main objectives of the study.

\section{Methodology}

The study design that were employed was specific time data based on the number of out relines from (2010-2018). The area where the study would cover was Amahara state and data used for this study were obtained from Amahara National state Agricultural office, Northern part of Ethiopia. In this study, the dependent variable was the variable that measures the performance of agricultural products in the case of Amahara National State and Agricultural output which is expressed in terms of quintal per hectare was used as the response variable.

Also, five potential explanatory variables were considered in this study. The descriptions of these covariant are presented in Table 1 below. 
Table 1. List of study variables.

\begin{tabular}{ccl}
\hline S/N & Variable & \multicolumn{1}{c}{ Description } \\
\hline 1 & GDP & Agricultural output expressed in terms of quantal per hectare \\
2 & Fertilizer & The amount of fertilizer used per hectare \\
3 & Labor force & The number of individual person used for work \\
4 & Improved seed & The type of seed used \\
5 & Irrigated land & The size of land which was irrigated \\
6 & pesticides & The amount of pesticides in litter per hectare to protect disease \\
\hline
\end{tabular}

\section{Method of Data Analysis}

Pearson correlation coefficient measures the linear relationship between the dependent variable and the independent variables. The correlation between any two variables always lies between $-1,1$ and 0 . If $r$ is -1 , this figure indicates that the dependent and the in-dependent variables have absolutely negative relationship while $r$ is 1 showing the existence of absolute positive relationship. But correlation coefficient of 0 implies that there is no any linear relationship between dependent and independent variables.

Regression analysis consists of techniques for modeling the relationship between a response variable and one or more explanatory variables or predictors and it answers questions about the dependence of a response variable on one or more predictors, including prediction of future values of a response, discovering which predictors are important, and estimating the impact of changing a predictor or a treatment on the value of the response. Consequently, this leads to use the multiple linear regression model in order to achieve the main and specific objectives of the study. Many methods have been developed to determine various parametric relationships between response variable and independent variables. These methods typically depend on the form of parametric regression function and the distribution of the error term in a regression model. Generally, most regression models are written as a function of predictor variables and random error.

$$
Y_{i}=f\left(x_{1}, x_{2}, \cdots, x_{k}\right)+\varepsilon_{i}
$$

where $k$ is the number of repressor's that are involved in the regression model, $Y_{i}$ is the additive random error term and $X_{i}=\left(x_{1}, x_{2}, \cdots, x_{n}\right)$ is a function that describes the relationship between $y$ and $x_{1}, x_{2}, \cdots, x_{k}$.

The parameters need to be estimated so that the model gives the best $\mathrm{t}$ to the data. These parameters are estimated based on least squares method principle. In this study the least squares principle was utilized to derive estimates of the regression parameters. Suppose that $n \geq k$ observations are available, and let $Y_{i}$ denote the $I^{\text {th }}$ observed response and $X_{i}$ denote the $I^{\text {th }}$ observation or levels of repressors $X_{i}$. Then the simple linear regression model of our study becomes:

$$
y_{i}=\beta_{0}+\sum_{i=1}^{n} \sum_{j=1}^{k} \beta_{j} x_{i j}, \quad k=1,2,3,4,5
$$


where,

$$
Y=\left[\begin{array}{c}
y_{1} \\
y_{2} \\
\vdots \\
y_{n}
\end{array}\right], \quad X=\left[\begin{array}{ccccc}
1 & x_{11} & x_{12} & \cdots & x_{15} \\
1 & x_{21} & x_{22} & \cdots & x_{25} \\
\vdots & \vdots & \vdots & & \vdots \\
1 & x_{51} & x_{52} & \cdots & x_{55}
\end{array}\right], \quad \beta=\left[\begin{array}{c}
\beta_{0} \\
\beta_{1} \\
\vdots \\
\beta_{k}
\end{array}\right], \quad \varepsilon=\left[\begin{array}{c}
\varepsilon_{1} \\
\varepsilon_{2} \\
\vdots \\
\varepsilon_{n}
\end{array}\right]
$$

The least squares principle for the multiple linear regression model is to find the estimates of the regression parameters such that the least squares function is small as possible. This least square regression function is determined by:

$$
\begin{gathered}
S(\beta)=\sum \varepsilon_{i}^{2} \\
S(\beta)=\varepsilon^{\prime} \varepsilon \\
S(\beta)=(y-x \beta)^{t}(y-x \beta)
\end{gathered}
$$

Using the concepts of calculus (matrix differentiation), the value of that minimizes the function $S(\beta)$ is $\left(x^{t} x\right)^{-1} x^{t} y$. Thus, the least square estimator of $\beta$ is given by:

$$
\hat{\beta}=\left(x^{t} x\right)^{-1} x^{t} y
$$

with the variance-covariance matrix of $\operatorname{var}(\beta)=\delta^{2}\left(x^{t} x\right)^{-1}$.

All statistical procedures and results extracted from such analysis are valid and have meaning only if the standard regression assumptions (linearity, non-stochastic repressors, no multi-linearity, zero mean error, no autocorrelation and normality) are satisfied. When these assumptions are violated, the standard results quoted do not hold and an application of them also lead to serious error. In addition, gross violations of the assumptions lead to an unstable model in the sense that a different sample could lead to a totally different models with opposite conclusions. The regression assumptions should be checked before drawing statistical conclusions from the analysis because the validity of these statistical procedures hinges on the validity of the assumptions. These assumptions are diagnosing using plot of standardized residuals against each of the predictor variables should be a random scatter points in the test of linearity, Plots of the standardized residuals against the predictors or against the fitted values are not only helpful to study whether a linear regression function is appropriate but also to examine whether the variance of the error terms is constant and using the a formal test of the Breusch-Pagan test for detecting the assumption of homoscedasticity. The most common measure of collinearity is the variance inflation factor for the $f^{\text {th }}$ regression coefficient $V I F_{j}$. The link between $V I F_{j}$ and collinearity (of the standardized and centered variables) is through the relationship

$$
V I F_{j}=\frac{1}{1-R_{j}^{2}}
$$

If $R_{j}^{2}$ equals zero (i.e., no correlation between $x_{j}$ and the remaining independent variables), then $V I F_{j}$ equals 1 . This is the minimum value of variance 
inflation factor. A VIF value greater than 10 is an indication of potential colinearity problems [14] and also the normality of residuals can be measured. A very simple method of checking the normality assumption is to construct a normal probability plot of the residuals. Substantial departures from a straight line indicate that the distribution is not normal. Furthermore, normality of residuals can be ensured by the Shapiro-Wilk normality test. Whenever data are obtained in a time sequence or some other type of sequence, such as for adjustment geographic areas, it is a good idea to prepare a sequence plot of the residuals. When the error terms are independent, we expect the residuals in a sequence plot to fluctuate in a more or less random pattern around the base line 0 . On the other hand, if we see a clustering of neighboring residuals on one or the other sides of the line $=0$, then such clustering is a sign that the errors are auto correlated. Lack of randomness can take the form of too much or too little alternation of points around the zero line. Plot the partial autocorrelation function (PACF) of ordinary least square (OLS) residuals is also one way of detecting the presence or absence of autocorrelation. All the bars should be within the confidence band if each residual is not predictable from the one preceding it. If the function at lag one is outside the $95 \%$ upper or lower confidence limits, then this is an indication that the errors follow the $\mathrm{AR}(1)$ process. Higher order error processes can be detected similarly. So the independence assumption may or may not be satisfied and to ensure this we can use Durbin-Watson (DW) test when the process is $\mathrm{AR}(1)$ and Breusch-Godfrey (BG) Test for higher order process.

\section{Result and Discussion}

The total agricultural products consist of 9 subsequent year's data from 2010 up to 2018. From this the statistical analysis results are presented in the graph below. From Figure 1, we observe that the total product increases sharply from

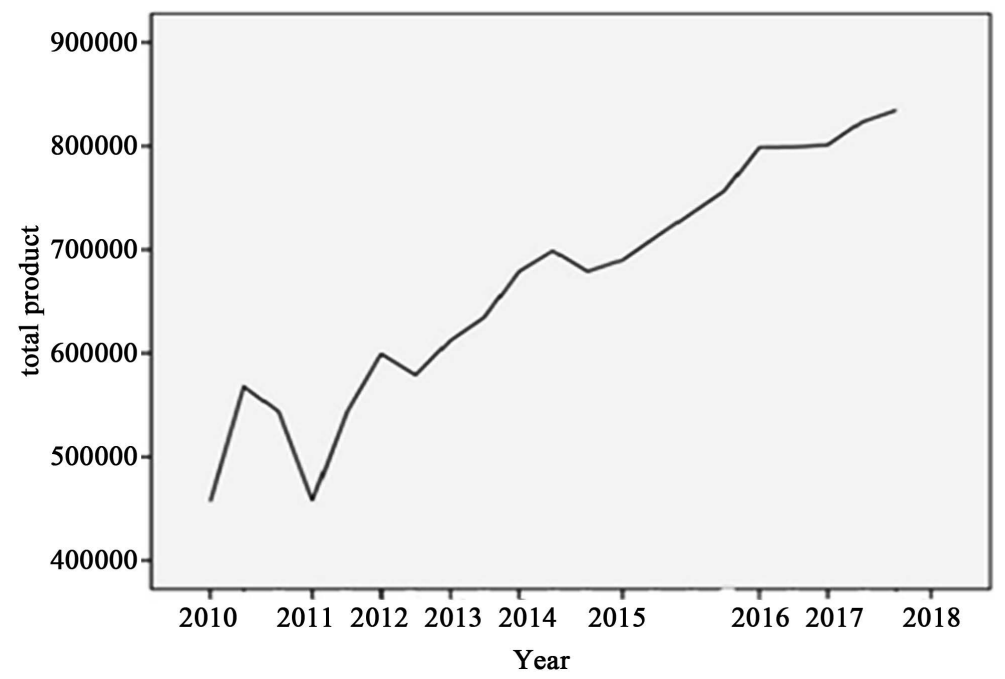

Figure 1. Production outputs in subsequent years. 
2010 to 2018. In half of 2011 the total products starts to decline and reaches minimum point in 2013, this is basically due to different reasons like change in policy in government, instability of country in poetics, draught and hence the agricultural sector cannot increase the output productions.

But after 2013 Starting from 2014 the total product starts to increase continuously throughout the year with a small decrement within the given years. From this we can understand that the total product is varying in different year. This variation is due to the use of different amount of basic input factors in different years (like improved seed, fertilizer, and irrigated land size). Examination of the results do not reveals any series violations of the assumptions. Thus, the usual interpretations of regression analyses are valid since all assumptions concerning the data were met.

Based on the shapiro-wilk normality test $(\mathrm{W}=0.9479)$ with a large $\mathrm{p}$-value ( $\mathrm{p}$ $=0.3106$ ), shows the residuals satisfy the normality assumption. Furthermore, we can see that the graph of normal Q-Q plot (the theoretical quintile's against the sample quintiles') from Figure 2, the residual observations lie nearly on the straight line of the graph or no any observation far from the line which implies that the normality assumption is fully satisfied. Thus this data are used for model building and for further statistical analysis as well as for future prediction purpose, because the violation of normality assumption is the basic question and problem of data analysis. The formal test of the studentized Breusch-pagan (BP) is 3.8432 with $\mathrm{p}$-value $=0.5722$ which is greater than $(\alpha=0.05)$ and plot of fitted values against the standardized residuals (there is no any systematic patterns), indicates the existence of homoscedasticity (constant variance), in other word the residuals has no any systematic patterns.

Since VIF is a measure of how much the variance of the estimated regression coefficient $\beta$ is inflated by the existence of correlation among the predictor variables in the model. A VIF of value less than 10 means that there is no correlation among the $k^{\text {th }}$ predictor and the remaining predictor variables, and hence

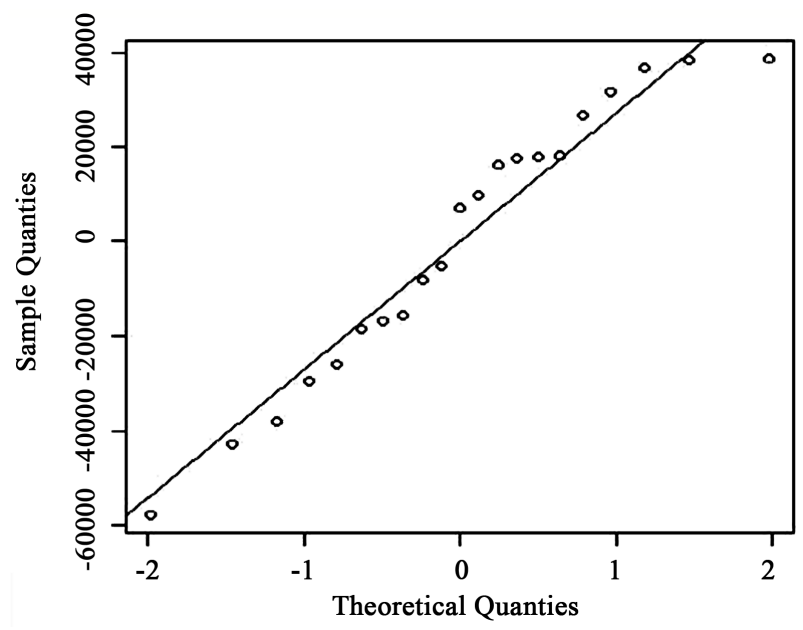

Figure 2. Normal Q-Q plot. 
the variance of $\beta$ is not inflated at all. From the result of Table 2, the VIF values for each variable are less than 10 indicating the non-existence of multi-collinearity. As the result of this we conclude that each of the independent variables are not correlated or no multi-collinearity among the explanatory variables.

In regression, this partial correlation could be found by correlating the residuals from two different regressions: one is we predict $y$ from $x_{1}, x_{2}, x_{3}, x_{4}$ and $x_{5}$, and secondly, we can also predict $x_{3}$ from $x_{1}$ and $x_{2}$. Basically, we correlate the parts of $y$ and $x_{3}$ that are not predicted by $x_{1}$ and $x_{2}$. According to Figure 3, all of the lags are found within the confidence limit (between -0.5 and 0.5 ). This leads to the conclusion that the error terms are not serially correlated or the assumption of no auto correlation between the error terms is satisfied. In this study the lag value is statistically significant, which suggests errors follow the AR(1) model for these data with no correlation.

After the overall test of model assumptions, the multiple linear regression model of the total output production over the significant explanatory variables was modeled based on the estimated values of the parameter, based on the individual $\mathrm{t}$-test for the significance of the individual predictor variables, based on the statistical results of Table 3 .

The fitting linear regression model that relating output product with the explanatory variables is given as:

$$
Y=-219625.734+46.882 x_{1}+94.03 x_{2}+21.63 x_{3}-151.119 x_{4}+0.427 x_{5}
$$

where $x_{1}, x_{2}, x_{3}, x_{4}$, and $x_{5}$ are the effect of pesticides, improved seed, labor force, fertilizer and irrigated land respectively. The model parameters were interpreted

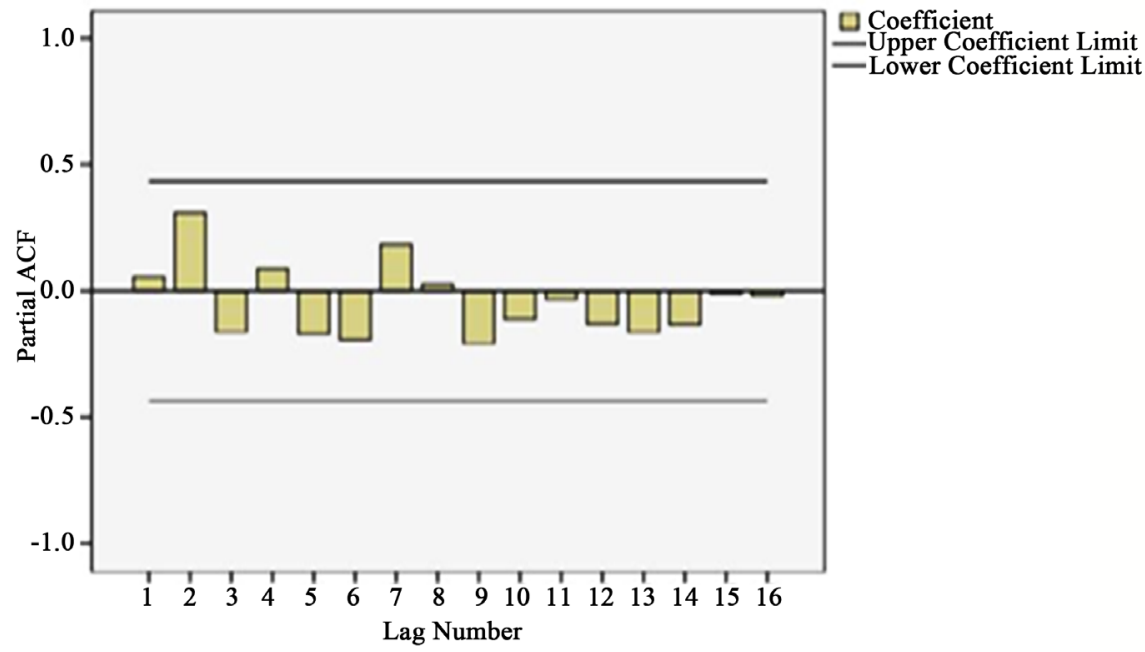

Figure 3. Partial autocorrelation function.

Table 2. Variance Inflation Factor of the explanatory variables.

\begin{tabular}{cccccc}
\hline Variables & Pesticides & Irrigated land & Improved seed & Labor force & Fertilizer \\
\hline VIF & 4.747158 & 6.395043 & 2.100014 & 1.170496 & 1.393434 \\
\hline
\end{tabular}


Table 3. Individual t-test of each of the predictor variables.

\begin{tabular}{ccccc}
\hline Effect & Estimate & Std. error & t-value & p-value \\
\hline Intercept & $-219,625.734$ & $1,996,540$ & -0.11 & 0.289 \\
Pesticides & 46.882 & 21.221 & 2.209 & 0.043 \\
Improved seeds & 94.030 & 34.762 & 2.705 & 0.016 \\
Labor force & 21.630 & 47.777 & 0.452 & 0.657 \\
Fertilizer & -151.119 & 43.682 & -3.460 & 0.00 \\
Irrigated land & 0.427 & 0.100 & 4.27 & 0.001 \\
\hline
\end{tabular}

R-square: 0.938 .

as follows. The figure $\beta_{1}=46.882$ indicate that when the use of pesticides increased by one litter per hectare the total product is also increased by 46.882 quintal where other effects are held constant. The figure $\beta_{2}=94.03$ also shows keeping other input factors constant, the total output production is increased by 94.03 quintals for every one quintal addition of improved seed. Similarly, for a unit increase in one hectare of irrigated land, the total agricultural product will increased by 0.427 quintal in similar way, $\beta_{4}=151.119$ reflects when the use of fertilizer increased by one quintal the total product decreased by 151.119 quintal. In fact this is not surprising because the used fertilizer might not be comfortable with the soil and it may reduce the total production output. Furthermore, the amount of used fertilizer might be excess (dose) and hence it may reduce the total production due to the acidic behavior of the fertilizer. The coefficient of determination is 0.938 from Table 3, shows that about $93.8 \%$ of the variation in the total output is explained by the explanatory variables, labor force, irrigated land, fertilizer, improved seed and pesticides while the remaining $6.2 \%$ of the variation is explained by other related factors like type of soil, temperature etc. If we take model size into account, $91.8 \%$ of the variation in average total agricultural output was explained by the values of the independent variables.

\section{Conclusion}

The explanatory study assessed the determinant factors for the performance of agricultural output production in Amahara regional state of the country, to make relevant recommendations about how other nonagricultural sectors transformed to agricultural sector. The discussion is centered on the most important findings in the importance of labor, the size of the irrigated land, fertilizer, improved seed and pesticides on the total output production. The econometric result analysis reveals that the relation-ship between fertilizer and output, labor force and output, irrigated land and output, pesticides and output as well as improves seed and output. Among this relations, irrigated land, pesticides, fertilizer and improved seed had a significant relation to output products with positive effect while has fertilizer had negative effect because of the soil in Amahara region has organic fertilizer, this is why fertilizer has negative effect on output 
production. Finally this study reveals the most important factors for agricultural output are: Irrigated land, fertilizer, improved seeds and pesticide were significant factors for agricultural out ensuring food security is a challenging endeavor, because of crop production of the region was affected by shallow soil which was very low in inorganic matter and extremely de deficient in nitrogen and phosphors. The average crop productivity (quintals/hectare) of the region is lower than the national average. In addition, the annual food grain consumption of the region is below the minimum daily requirement of 2400 calories per person. There are also many households in the list of the Productive Safety Net Program (PSNP) who are unable to fill the annual food requirements of their families.

\section{Acknowledgements}

The author is grateful to the Editor of Agricultural Sciences (AS) in Scientific Research Academic Publisher and anonymous referees for their helpful comments and suggestions on the earlier version of this article.

\section{Conflicts of Interest}

The authors declare no conflicts of interest regarding the publication of this paper.

\section{References}

[1] Lefort, R. (2012) Free Market Economy, Developmental State and Part State Hegemony in Ethiopia: The Case of the Model Farmer. Journal of Modern African Studies, 50, 681-706.

[2] Centeral Statistical Autority (2007) Crop Production Sample Survey Statistics Bulletin.

[3] Centeral Statistical Autority (2008) Summary and Statistical Report of the 2007 Population and Housing Census: Population Size by Age and Sex. UNFPA, Addis Ababa, Ethiopia.

[4] Barrios, S., Strobl, E. and Ouattara, B. (2008) The Impact of Climatic Change on Agricultural Production: Is It Different for Africa. Food Policy, 33, 287-298. https://doi.org/10.1016/j.foodpol.2008.01.003

[5] MoFED (2012) Sustainable Development and Poverty Reduction Program. Addis Ababa, Ethipia.

[6] Tadaro, M. (1995) Economic Development. 5th Edition, New York University, Singapore.

[7] World Bank (1996) From Plan to Market-Executive Summary (Russian). World Development Report, World Bank Group, Washington DC.

[8] Minsrty of Planining and Economic Development (1998) Trends on Development and Annual Report on Macroeconomic Development in Ethiopia.

[9] Hussain, I. and Hanjra, M.A. (2004) Irrigation and Poverty Alleviation: Review of the Empirical Evidence. Irrigation and Drainage, 53, 1-15. https://doi.org/10.1002/ird.114

[10] Echer and Staatz (1998) International Agricultural Development. 3rd Edition, The Johns Hopkins University Press, Baltimore. 
[11] Todaro, M. (2000) Economic Development. 7th Edition, Addison Wesley Inc., England.

[12] Liebenstcin, H. (1996) Allocative Efficiency vs. X-Efficiency. American EcOM.

[13] Carter, M. (1984) Issues in the Hidden Economy-A Survey. Economic Record, 60, 209-221. https://doi.org/10.1111/j.1475-4932.1984.tb00856.x

[14] Hair, J. and Anderson, R. (1995) Multivariate Data Analysis. 3rd Edition, Macmillan, New York. 